\title{
RESSURGIMENTO, CONSOLIDAÇÃO E RUPTURAS: REPRESENTAÇÕES COLETIVAS SOBRE FUTEBOL E IDENTIDADE NACIONAL NO URUGUAI (2010-2013)
}

\author{
RESURGENCE, CONSOLIDATION AND SPLITS: COLLECTIVE REPRESENTATIONS \\ ON FOOTBALL AND NATIONAL IDENTITY IN URUGUAY (2010-2013)
}

\author{
Cristian Maneiro \\ Wanderley Marchi Júnior ${ }^{2}$
}

\section{RESUMO}

\begin{abstract}
0 trabalho apresenta, de forma panorâmica, os objetivos e considerações gerais da dissertação de mestrado do autor atualmente em andamento. A mesma propõe analisar as possibilidades de expressão e reprodução da identidade nacional uruguaia através do futebol. Concretamente, abordar a contribuição específica das representações coletivas construídas interna e externamente, sobre o desempenho da seleção uruguaia de futebol entre os anos 2010-2013, focando em três momentos específicos: A Copa do Mundo África do Sul 2010, a Copa America Argentina 2011, e as Classificatórias para Copa do Mundo Brasil 2014. Analisaram se, desde uma perspectiva qualitativa e utilizando técnica de análise de conteúdo, as matérias jornalísticas aparecidas no período selecionado tanto nas principais fontes de imprensa esportiva uruguaia como nos organismos reguladores num nível global: Fedération Internationale de Football Asociation (FIFA) e Confederación Sudamericana de Fútbol (CONMEBOL). 0 artigo começa estabelecendo os objetivos gerais e específicos da dissertação. Posteriormente se apresenta o referencial teórico a utilizar para explorar os três conceitos considerados chaves (Identidade Nacional, Representações Coletivas e Mitos) e se contextualiza brevemente a historia do futebol no Uruguai desde os começos de sua pratica ate o período de interes. Para finalizar destacam se algumas conclusões preliminares obtidas após uma primeira codificação e analise dos dados.
\end{abstract}

Palavras Chave: Futebol, Identidade Nacional, Representações Coletivas, Mitos, Uruguai

\section{ABSTRACT}

\begin{abstract}
This paper presents an overview of the objectives and general considerations of a master degree dissertation currently in progress. Such dissertation aims at analyzing the possibilities of expression and reproduction of uruguayan national identity through football. Particularly, the aim is to analyze the contribution of those collective representations built internally and externally, about the performance of the uruguayan national team for the period 2010-2013, focusing on three specific moments: World Cup 2010, American Cup 2011, and World Cup Qualifyiers 2014. From a qualitative perspective, using content analysis techniques, there will be analyzed the press notes generated on that period from uruguayan media as well as from the governing bodies at a global level: Fedération Internationale de Football Asociation (FIFA) and Confederación Sudamericana de Fútbol (CONMEBOL). The paper begins introducing its general and specific aims, then they are described the theoretical foundations to explore the three key concepts (National Identity, Collective Representations and Myths). Afterwards its is briefly contextualized the history of football in Uruguay from its beginnings to the period of interest. Finally, they are presented some preliminary conclusions after a first codification and analyisis of the data.
\end{abstract}

Keywords: Football, National Identity, Collective Representations, Myths, Uruguay

Fecha de recepción: 15 de julio de 2014

Fecha de aprobación: 1 de noviembre de 2014

1 Universidade Federal do Paraná (UFPR), Brasil. Correo electrónico: cristianmaneiro22@gmail.com

2 Universidade Federal do Paraná (UFPR), Brasil. Correo electrónico: wmarchijr@gmail.com 
Para citar este artículo:

Maneiro, C., Marchi, W. (2014). Ressurgimento, consolidação e rupturas: representações coletivas sobre futebol e identidade nacional no Uruguai (2010-2013). Revista Lúdica Pedagógica, (20), 59-65.

\section{INTRODUÇÃO:}

0 presente trabalho, correspondente à dissertação de mestrado em andamento, busca analisar as possibilidades de expressão e reprodução da identidade nacional uruguaia através do futebol a partir da contribuição específica das representações coletivas, construídas interna e externamente, sobre o desempenho da seleção nacional entre os anos 2010-2013. Foca se em três momentos específicos: a Copa do Mundo da África do Sul 2010 (CM2010) a Copa America Argentina 2011 (CA2011), e as Classificatórias para a Copa do Mundo Brasil 2014 (CL2014).

Para atingir este objetivo, propõe-se partir das distintas teorias consideradas pertinentes para explicar a formação e reprodução da identidade em sua vertente nacional, assim como dos vários trabalhos antecedentes num nível nacional e regional sobre o processo de consolidação de representações coletivas em torno do futebol.

A análise será desenvolvida por uma perspectiva qualitativa e utilizando principalmente a técnica de análise de conteúdo (Bardin, 1996), tendo como insumos as matérias das principais fontes de imprensa uruguaia e dos organismos reguladores do futebol em nível global: Fedération Internationale de Football Asociation (FIFA) e Confederación Sudamericana de Fútbol (CONMEBOL).

Propõe-se a seguinte pergunta norteadora: ¿Quais são os elementos identitários apontados e como são mobilizados pela mídia uruguaia e os organismos reguladores para representar à seleção de futebol do Uruguai nos recentes eventos futebolísticos globais (CM2010; CA2011; CL2014). A partir desta pergunta central são colocadas perguntas específicas relativas a como são atualizadas as velhas representações coletivas tradicionais sobre o futebol uruguaio, e como são construídos discursivamente os "heróis" da seleção nesse período.

Com base nestas perguntas, o objetivo geral formula-se da seguinte maneira: Analisar as possibilidades de expressão e reprodução da identidade uruguaia através da contribuição especifica das representações coletivas fornecidas pela imprensa uruguaia e os organismos reguladores internacionais, sobre o desempenho da seleção uruguaia de futebol entre os anos 2010-2013.
Estabelecemos também uma série de objetivos específicos, quais sejam: Contextualizar historicamente a importância do futebol na expressão e reprodução das autoimagens identitarias uruguaias; Descrever os discursos transmitidos pela imprensa escrita uruguaia e os organismos reguladores internacionais sobre o desempenho da seleção uruguaia no período 2010-2013, apontando as continuidades e rupturas em relação às representações coletivas tradicionais sobre futebol uruguaio; Identificar os processos de construção discursiva de heróis esportivos neste período.

No que diz respeito à importância do futebol num nível social, através de distintos discursos principalmente políticos, se aponta que pela importância histórica que esta modalidade esportiva tem no nível de aderência popular no país, deveria tentar ser usado como um elemento da integração social, através de políticas públicas que estimulem a educação e socialização através do esporte, um estilo de vida saudável e a erradicação da violência em distintos ambitos ${ }^{3}$. Esta importância social se entende considerando que o futebol consolidou se historicamente como elemento identitário no Uruguai, sendo o esporte mais popular desde os começos da sua prática no país até hoje. Podemos dizer que por meio da identificação coletiva com a equipe nacional os habitantes desse país se reconhecem em algo além de si mesmos depositam sua autoestima, e fazem catarses coletivas através dos sucessos e frustrações esportivas

Um país territorial e demograficamente pequeno ${ }^{4}$, e sem uma grande influencia nos processos comerciais e políticos ao nível mundial, tem encontrado historicamente uma possível e bem sucedida forma de reconhecimento global através de sua seleção nacional de futebol. Já nos começos do século XX as conquistas futebolísticas foram uma forma privilegiada de dar visibilidade ao país, colocando o Uruguai no mapa mundial. Nesta época globalizada este potencial se reforça, com as consequências que este fato pode trazer em termos de promoção turística e investimentos (consequências explicitamente aceitas e exploradas pelos governantes e pessoas ligadas à área econômica) ${ }^{5}$.

3 Ver palavras do técnico Tabaréz após ser distinguido pelo governo uruguaio: http://espndeportes.espn.go.com/news/ story?id=1344695\&s=futbol/copa-america\&type=story) Acesso 28/11/2013

4 Uruguai tem um tamanho de $176.215 \mathrm{~km}^{2}$ e segundo o ultimo censo demográfico do ano 2011 a população e de 3.286.314 habitantes (www.ine.gub.uy). Acesso 25/05/2014.

5 Ver as declarações do ministro de turismo no lançamento da campanha "Uruguay Natural" com Diego Forlan. http:// www.montevideo.com.uy/notnoticias_123900_1.html Acesso $28 / 11 / 2013$ 
Neste sentido, acreditamos que a análise das representações coletivas sobre o futebol, pode ser uma boa aproximação à compreensão da autoimagem nacional historicamente construída e às inter-relações que se estabelecem entre a autoimagem e as visões externas.

Por sua vez, num nível acadêmico, acreditamos que a relevância desta pesquisa reside na sua capacidade de lidar com diferentes problemas e debates de longa data nas ciências sociais: o potencial de determinados eventos para gerar identidades e representações coletivas duráveis e o papel que desempenham os meios de comunicação nesse processo.

0 trabalho constrói-se como uma contribuição original sobre um problema de pesquisa do qual muito tem se escrito no âmbito jornalístico, mas ainda pouco sob um olhar sociológico. Embora existam antecedentes acadêmicos sobre os primeiros anos do futebol uruguaio, os resultados desta pesquisa terão sua contribuição específica e distintiva no que diz respeito à análise dos últimos anos das participações da seleção de futebol em torneios globais assim como respeito à metodologia $\mathrm{e}$ as fontes utilizadas para a análise.

Neste sentido, um meta-objetivo do trabalho é reivindicar a utilidade das ciências sociais para abordar estes processos e fornecer outra interpretação sobre eles que complementem a hegemonia dos discursos jornalísticos, literários e políticos sobre os mesmos.

\section{FUTEBOL E IDENTIDADE NACIONAL: PERSPECTIVAS TEÓRICAS}

O trabalho baseia se em três conceitos teóricos chaves: Identidade Nacional, Representações Coletivas e Mitos, que serão os eixos ao redor dos quais se desenvolverá a análise.

Partimos de definir a identidade desde uma concepção processual, entendendo-a como um resultado emergente de um duplo processo que compreende a simultânea inclusão e exclusão de grupos. Neste sentido, Identidade e alteridade possuem uma parte comum e encontram-se numa constante relação dialética. Através das interações constantes entre a auto-imagem e as imagens externas vai se conformando a cada momento a identidade pessoal ou grupal (Mead,1982; Cuche, 1999).

Desde esta base, e segundo antecedentes teóricos, vamos considerar a nação como um dos elementos identitários mais importantes, por sua capacidade para gerar laços sociais e emocionais entre as pessoas. Os indivíduos que se identificam com uma nação particular possuem uma série de valores, símbolos e tradições compartilhadas que lhes da um sentido de pertença ao tempo que os diferencia de outras pessoas e grupos. Supõe uma identificação com uma entidade supra pessoal, assim como características pessoais reconhecidas e reconhecíveis por membros externos ao grupo (Anderson, 1993; Elías, 1997).

O conceito de hábitus nacional como formulado por Elias nos ajuda a repassar os processos sociais pelos quais foi estabelecida historicamente a conformação dessa identidade nacional, sendo uma alternativa teórica viável para superar a noção ambígua de caráter nacional como algo fixo e imutável. A configuração de uma sociedade dada, no que diz respeito à sua estratificação social, as relações entre classes dirigentes e subordinadas, o pensamento das elites econômicas, políticas e culturais a cada período histórico, vão conformando o tal hábitus nacional a cada instante (Elías, 1997). Também analisamos as tensões e possibilidades de supervivência desta identidade nacional no atual contexto globalizado, através da categoria do nacionalismo esportivo (Bairner, 2001) segundo a qual e no esporte a identidade nacional encontra oportunidades de manifestação frente às tendências homogeneizantes que apresenta a globalização.

Os elementos s que o futebol uruguaio fornece para a geração e expressão identitária dessa nação, são abordados desde o conceito de representações coletivas entendidas enquanto elementos não somente expressivos más também cognitivos. Trata se de uma forma de conhecimento de caráter social e histórico produzidas por uma cooperação prolongada no espaço e no tempo entre varias gerações de pessoas numa sociedade concreta (Dhurkeim, 2003). Neste sentido, as representações coletivas expressam a maneira pela qual um grupo particular se enxerga a si mesmo nas relações com os objetos e pessoas que o afetam na sua vida cotidiana. Apresentam um caráter historicamente resistente e certa autonomização, já que embora apareçam em instâncias específicas de indivíduos reunidos, rapidamente ganham um caráter autônomo e se apresentam como externas aos indivíduos (Durkheim, 2003).

Por último, o conceito antropológico do Mito será usado na versão do mito do herói (Campbell, 1997), especialmente quando aplicado ao atleta como herói contemporâneo. Neste sentido, os atletas-heróis desempenham um papel de representação da comunidade e seu sucesso pode ser atribuído ao fato de eles serem capazes de transpor obstáculos impossíveis de superar pela comunidade que os idolatra (Rubio, 2001). Desde esta base, vamos 
empregar os distintos autores que descrevem as fases do "ciclo" do herói (saída do lar, provas que deve ultrapassar, retorno triunfante) apoiando-nos também nos diversos antecedentes regionais sobre a construção de heróis futebolísticos nacionais como os casos de Romário (Helal, 2003) ou Ronaldo (Albuqerque, 2013) no Brasil, assim como as analises do Maradona na Argentina (Archetti, 2001). Através destas referências procuraremos interpretar os mecanismos discursivos de construção de ídolos na seleção uruguaia nos período analisados.

\section{BREVE HISTÓRIA DO FUTEBOL NO URUGUAI.}

Para situar o nosso trabalho no contexto sócio-histórico uruguaio e importante referir brevemente os antecedentes quanto ao surgimento e desenvolvimento do futebol nesse país.

Introduzido pelos primeiros ingleses que chegaram a costa uruguaia nas últimas décadas do século XIX, e de pratica inicialmente restrita as elites o futebol vai aos poucos se estendendo na sua pratica e experimentando um lento mas constante processo de hibridização e crioulização que o transformam gradualmente no jogo nacional por excelência, à todos os estratos sociais (Morales, 2013).

Durante os começos do século XX o selecionado uruguaio domina o mundo do futebol. Os trunfos olímpicos em 1924 e 1928, assim como no primeiro campeonato mundial em 1930, começam a gerar diferentes explicações e interpretações, principalmente por parte dos meios de comunicação, formando a incipiente identidade futebolística crioula. A principal oposição apontada é entre o estilo crioulo do Rio de la Plata, e o estilo europeu. De acordo com esta distinção, o estilo crioulo baseia-se na elegância e improvisação, enquanto o europeu expressa a força e a disciplina (Archetti, 1995). Os triunfos acima mencionados, geraram uma narrativa midiática que atribuía ao estilo de futebol uruguaio características únicas como astúcia, ousadia, e imprevisibilidade sintetizadas na expressão viveza criolla.

Estes triunfos ligavam se a um momento de auge do país na arena internacional. O Uruguai apresentava condições econômicas e sociais favoráveis, enquanto Europa se encontrava na crise do período do pós-guerra, o que iria reforçar a autoimagem da singularidade uruguaia como "Suíça de América” (Bayce, 2003).

Como uma continuação destes sucessos iniciais, e como a última grande vitória da geração olímpica, Uruguai obtém o campeonato sul-americano em 1935. Neste campeonato de 1935 é que emerge no nível dos discursos jornalísticos o mito da garra charrúa, trás vencer a competição com um time veterano e ganhando a final ao time argentino que era o favorito. Os charrúas eram a tribo indígena majoritária no território que posteriormente seria o Uruguai. As crônicas da época referem a eles como uma raça indômita, feroz, rebelde a toda a civilização, essencialmente guerreiros e turbulentos (Faccio, 2006). Daí que a garra charrua faz referência simbólica a estes atributos guerreiros e a uma raça que apareceria nos momentos chave para atingir sucessos racionalmente impensáveis em termos futebolísticos.

Assim como durante os anos 20 e até o mundial de 1930 surgira a representação da viveza criolla como uma virtude rioplatense, após 1935 apareceu e consolidou se a garra charrúa como explicação adicional para vitórias esportivas. Trata se de uma característica exclusivamente uruguaia o que serve ao mesmo tempo para especificar o caráter nacional e assim diferenciar se da Argentina.

Esta representação coletiva terá o seu auge narrativo em 1950, quando o Uruguai ganha a final da Copa do Mundo desse ano no Brasil num acontecimento que ficou conhecido como Maracanazo e representa a pior tragédia contemporânea do Brasil e o maior sucesso do futebol uruguaio até hoje.

Nessa ocasião a figura de Obdulio Varela, capitão daquele time uruguaio, apelidado negro jefe, é apresentado como a personificação da garra charrua, ressaltando especialmente sua personalidade e liderança naturais, a influência em companheiros e rivais, sua origem humilde e as diversas dificuldades, que teve de ultrapassar (Mancuso, 1973) características que vão conformar o arquétipo dos heróis futebolísticos uruguaios.

A garra ficou como uma marca duradoura do futebol uruguaio nos anos seguintes. Porém, após a derrota para a Hungria em semifinais na copa de 1954, o pais ficaria fora da copa em 1958 enquanto em 1962 acabaria não superando a primeira fase. Teria que se esperar até 1970 para que o time uruguaio chegasse novamente às semifinais. 0 futebol uruguaio entrava lentamente num ostracismo, que vai se estender por décadas (Morales, 2013). Após a copa de 1970, a presença uruguaia nas copas começou a ser cada vez mais irregular, ficando por fora das copas de 1978, 1982, 1994, 1998 e 2006 e sem alcançar nem as quartas da final no resto das copas em que efetivamente participou. 
$\mathrm{Na}$ opinião de alguns estudiosos, este ostracismo se explica porque os triunfos obtidos até 1950 foram essencializados o que inibe uma consideração aprofundada e desapaixonada das condições sócio-históricas que fizeram possível essas performances esportivas. A distância crescente entre esse passado glorioso e o presente frustrante, ajudaram a apagar os contornos daquelas vitórias, minimizando por exemplo o fato de que foram em torneios envolvendo poucos equipes e com a juventude europeia dizimada pelas guerras mundiais. A essencialização da "garra charrúa" como elemento capaz de ganhar partidas por si mesmo, teve consequências negativas na despreocupação pela preparação física e atualização tática necessária, o que fez com que enquanto muitos outros países se desenvolveram futebolisticamente, o Uruguai estancou-se. (Bayce, 2003).

Porém, podemos pensar segundo Durkheim (2003) que se mesmo com estas desavenças históricas as representações persistem é porque são de alguma forma atualizadas periodicamente. Neste sentido cabe retomar as nossas perguntas de pesquisa: como as velhas representações coletivas tradicionais são atualizadas neste contexto dos sucessos recentes? Assim como foi mitificada a figura de Obdulio Varela, como são construídos discursivamente os heróis atuais da seleção?

\section{RESSURGIMENTO, CONSOLIDAÇÃO, RUPTURAS.}

Pelo fato da dissertação estar em andamento, tendo apenas finalizada a coleta de dados e sendo desenvolvida atualmente a etapa de análise e redaçao, não temos ainda conclusões definitivas. Porém, através de uma primeira leitura e codificação dos dados, é possível traçar algumas considerações preliminares.

O bom desempenho da seleção uruguaia na CM2010 foi definido pela imprensa nacional de duas formas principais: como sendo resultado direto de fatores como esforço coletivo e trabalho em equipe, mas principalmente como um renascimento de um futebol uruguaio que encontrava se num prolongado ostracismo, sendo revitalizadas discursivamente as velhas representações sobre a "garra charrúa" como explicações dos sucessos.

Estas construções nacionais interagem com os discursos dos organismos reguladores, que as adotam e as transmitem, apresentando para o mundo futebolístico uma imagem atualizada das representações coletivas históricas do futebol uruguaio. Desta maneira construiu-se a identidade nacional de maneira processual e pode se falar de um ressurgimento do futebol uruguaio.
Uruguay recibió este martes al equipo Celeste que logró despertar el orgullo y reverdecer los históricos laureles futbolísticos de la nación sudamericana. (FIFA; 13/07/2010)

O sucesso obtido na CA2011 representaria o ponto de consolidação do "Processo Tabarez", uma confirmação de que Uruguai estava de volta nos primeiros planos do futebol mundial, exibindo a condição do melhor time do continente por sobre os tradicionais rivais Argentina e Brasil.

Esta copa tenia que llegar, es la que renueva la ilusión, la que enseña el camino por el cual hay que transitar y hay que reconocer que se lo merecían los valientes herederos de una raza de campeones (ANUARIO OVACION 2011)

Porém, acreditamos que estas construções, geradas interna e externamente, apresentam uma ruptura nas CL2014, quando após um começo positivo, os resultados começam a ser desfavoráveis. Nesse momento, muitos dos elementos conceituados até esse momento como fortemente positivos e diferenciais do Processo Tabarez (estabilidade emocional, humildade e clareza do técnico, bom nível de certos jogadores, comportamento exemplar dentro e fora dos gramados, união grupal) passam a ser questionados pela mídia. Quando o objetivo de se classificar para a Copa do Mundo do Brasil 2014 finalmente é atingido voltariam a ter presença discursiva os elementos destacados anteriormente.

Para cada um destes momentos, pretendemos aprofundar a analise e avaliar através dos discursos midiáticos como se relacionam com as representações coletivas geradas no passado.

Numa análise preliminar, a CM2010 apresenta momentos chave como a partida contra Ghana, onde consideramos que a mão do Suarez pode servir como exemplo de expressão da "viveza criolla" e as boas partidas contra as potencias europeias como Holanda e Alemanha, que acabaram com vários jogadores machucados pelo esforço, seriam um renascer da "garra charrua" e a "mística celeste" que permite obter resultados que eram impensados antes de começar a competição. Neste sentido, a representação histórica segundo a qual Uruguai seria o pais com maior glória per/cápita, dada a não correspondência do tamanho do país com os sucessos obtidos, também aparece nas matérias internas e externas antes e depois da competição. 
Uruguay volvió a sus raíces más profundas, a esas que lo llevaron a lo más alto, aquellas que lo vieron ganar todo y en la adversidad... la selección nacional recuperó en Sudáfrica el prestigio que había quedado en el olvido para el resto del mundo (OVACION DIGITAL 11/07/10)

El equipo se fortalece a través del espíritu. Entra a dar batalla en todos los partidos. Volvió la Celeste. Un equipo con sangre charrúa. Es lo que esperábamos ver. (OVACION DIGITAL 23/06/10)

Pocos equipos cuentan con la historia futbolística que ostenta Uruguay....Con apenas poco más de 3 millones de habitantes, puede presumir de haber conquistado títulos mundiales, olímpicos y continentales ... No obstante, la época de aquellos lauros parecen haber quedado lejos en el tiempo. (FIFA, $10 / 06 / 2010$ )

Na CA2011 se atualizam estas representações, especialmente na marcante vitória contra a Argentina nas quartas de final. 0 dramatismo da definição por pênaltis, derrotar o dono de casa e histórico rival jogando boa parte da partida com um jogador a menos, e que o jogo tenha acontecido num 16 de julho (mesma data do maracanazo) são elementos que ligam simbolicamente ao passado e possibilitam a atualização das velhas representações coletivas, sendo por amplio margem a partida que gerou maior numero de matérias.

As oscilações esportivas experimentadas durante os dois anos de duração das CL2014 por sua vez, brindam uma interessante oportunidade para avaliar a capacidade de resistência dessas representações coletivas frente aos diversos questionamentos recebidos num momento de crise. Se nos momentos anteriores as criticas foram mais bem tímidas, e neste momento onde explicitamente se questionam alguns jogadores, se exige a renovação da equipe e se chega até a pedir a demissão do técnico.

Lo de Uruguay fue pobre y el resultado pone las cosas más feas en las Eliminatorias. Lo peor es que no fue un incidente, es una tendencia. (OVACION DIGITAL 12/09/12)

Tabárez falló. No dio ninguna respuesta como conductor ...Ahora, si no cambia, ló van a tener que cambiar (OVACION DIGITAL 17/10/12)

Outro eixo de análise transversal aos três momentos, será a construção discursiva dos heróis esportivos. 0 foco é colocado naqueles membros da seleção que mais aparecem nas matérias nacionais e internacionais (Forlán, Lugano, Suarez, Tabárez). Através da análise de suas biografias e entrevistas se apontam as principais características pessoais que são ressaltadas pela mídia para merecer a condição de heroís, estabelecendo se as possíveis continuidades e também rupturas entre estas construções e os históricos heróis esportivos do time nacional. Serão analisadas tambem as críticas recebidas e os modos de vilanização (Albuquerque, 2013) destes heróis nos momentos de crise esportiva.

A análise preliminar sugere a presença de algumas ideias recorrentes, podendo ser encontradas nos três momentos analisados: a valorização da coesão grupal como elemento diferencial deste processo de seleções, o maior grau de profissionalização experimentada em relação ao passado, o suposto sentimento de "união nacional" que estava adormecido e os sucessos da seleção revitalizaram. Também aparece como um possível eixo de análise as distintas tentativas, mais ou menos sutis, de aproveitamento político dos bons resultados esportivos.

No desenvolvimento da dissertação pretende se refinar a codificação e categorização das matérias selecionadas para assim aprofundar nestas explicações preliminares.

\section{REFERENCIAS BIBLIOGRÁFICAS}

Albuquerque, E. (2013). A mídia e o mito do Herói: analisando as matérias do caderno de esportes da folha de São Paulo a partir do caso Ronaldo (2008-2011). Curítiba, Dissertação Mestrado em Educação Física, Departamento de Educação Física, Universidade Federal do Paraná,

Anderson, B. (1993). Comunidades imaginadas. México: Fondo de Cultura Económica.

Archetti, E. (1995). Estilo y virtudes masculinas en EL Grafico: La creación del imaginario del futbol Argentino. Desarrollo Económico - Revista de Ciencias Sociales, 35, (139), 419-442.

Archetti, E. (2001). The spectacle of a heroic life: the case of Diego Maradona. En Jackson, S. (2001). Sport Stars: The Cultural Politics of Sporting Celebrity, New York: Routledge,

Bairner, A. (2001). Sport, nationalism, and globalization: European and North

American perspectives. Albany: New York State University of New York Press, 
Bayce, R. (2003). Cultura, identidades, subjetividades y estereotipos: preguntas generales y apuntes específicos en el caso del fútbol uruguayo. En Alabarces, $\mathrm{P}$. (2003). Futbologias, Fútbol, identidad y violencia en América Latina. Buenos Aires: CLACSO.

Bardin, L. (1996). Análisis de Contenido. Madrid: AKAL Universitaria.

Campbell, J. (1997). O Heroi das mil faces. São Paulo: Cultrix/ Pensamento.

Durkheim, E. (2003). As Formas Elementares da Vida Religiosa. São Paulo: Martins Fontes.

Elías, N. (1997). Os alemães. Rio de Janeiro: Zahar.

Faccio, F. (2006). El futbol como espacio de producción de identidad: Acerca de la Garra Charrúa. Montevideo, IV Jornadas de Investigación Científica, FCS.

Helal, R. (2003). Idolatría e malandragem: a cultura brasileira na biografia de Romario. En Alabarces, P. (2003). Futbologias, Fútbol, identidad y violencia en América Latina. Buenos Aires: CLACSO.
Mancuso, R. (1973). Obdulio, el último capitán. Montevideo: Imprenta Panamericana.

Mead, G. (1982). Espíritu, persona y sociedad. Barcelona: Paidos.

Morales, A. (2013). Futbol, Identidad y Poder 1916-1930. Montevideo: Editorial Fin de Siglo.

Rubio, K. (2001). O atleta e o mito do herói: o imaginário esportivo contemporâneo. São Paulo: Casa do Psicólogo.

\section{FONTES CONSULTADAS}

Arquivo Ovacion Digital: www.historico.ovacion.com.uy Anuario 2010 Caderno Esportivo Ovacion Digital.

Anuario 2011 Caderno Esportivo Ovacion, Digital.

Site Web FIFA: http://es.fifa.com/index.html

Site Web Conmebol: www.conmebol.com 